\title{
The effect of the organic plant protection system on the chemical composition and quality of grapes and red wines
}

\author{
Elena Ostroukhova, Irina Peskova ${ }^{*}$, Natalia Lutkova and Elena Stranishevskaya \\ All-Russian National Research Institute of Viticulture and Winemaking Magarach of the RAS, Yalta, \\ Republic of Crimea, Russia
}

\begin{abstract}
The biologization of viticulture is considered as a necessary attribute of its effective functioning, aimed at reducing environmental and economic risks. Comparative studies of the effect of conservative system of agriculture, including chemical crop protection, and the organic system with using preparations Extrasol, Respecta, Chitosan, Tiovit Jet on physicochemical indicators and quality of grapes and wines were carried out. We used grape cultivar 'Bastardo magarachskiy' from the South Coast area of Crimea. It was found that using preparations in the organic farming system contributed to the accumulation $(\alpha<0.05)$ of sugars in berries on average by $15 \%$, phenolic compounds - by $13-22 \%$, anthocyanins - by $23 \%$, and PPO activity of the must. Experimental schemes of treatment did not influence the accumulation of aldehydes in berries. Their effect on the content of ketoacids was determined by the crop year conditions. Experimental wines were distinguished by a higher $(\alpha<0.05)$ content of ethyl alcohol, phenolic compounds (on average by $46 \%$ ), anthocyanins (1.6 times), pyruvic and $\alpha$-ketoglutaric acids (1.6 and 1.9 times) and a lower (by $20 \%$ ) concentration of aldehydes. Experimental schemes of treatment did not influence on the organoleptic of wines. The best result was shown by the complex of Tiovit Jet and Extrasol.
\end{abstract}

\section{Introduction}

Currently, the biologization is a necessary attribute of modern adaptive landscape agriculture and a condition for its effective functioning. The necessity to reduce chemical load by using biological preparations is due to a number of negative environmental and economic consequences. At the same time, lack of significant positive results of using biological preparations in agricultural practice is possibly due to the fact that they are used without taking into account the relationships and interactions between factors: some biological preparations, which are quite active in natural phytocenoses, are depressed in agrophytocenoses due to the intensive chemical and technogenic system of agriculture [13]. Despite this, the results of a number of studies show that microbiological preparations are effective in reducing the infectious load of the top soil, anthropogenic load. They can be

\footnotetext{
* Corresponding author: yarinka-73@mail.ru
} 
used as biological fertilizers, contributing to the accumulation of phosphorus available for plants, nitrogen fixation, etc. [4]. The effectiveness of biological preparations used in the cultivation of a number of agricultural crops - spring wheat, barley, oats, potatoes, maize, etc. - is out of question now [5, 6]. Nowadays biological preparations are widely used in the vineyards of Crimea [7]. The research carried out in the FSBSI Institute Magarach of the RAS showed that using of biological preparations allows to control the development of oidium, as well as to exclude outbreaks of mass development of garden spider mite and grape moth in vineyards [7]. As can be seen from the previously conducted studies, the organic protection system used on the 'Bastardo magarachskiy' grape cultivar was not inferior to the traditional treatment scheme in terms of effectiveness and influence on the composition of a grape berry [8].

Literary sources show contradictory information about the effect of the organic farming system on the composition and quality of fruits. So, Reganold J.P. et al. [9] noted that strawberries grown in the conditions of organic farming were superior in quality to berries grown in the conditions of traditional farming. According to the research of Oliveira A.B. et al. [10], using of the organic farming system contributed to a better quality of apples with more sweet and less astringent flavor. Xiaofan $\mathrm{Yu}$ et al. and A. Miele say that organic products, including grapes, are distinguished by a more delicate flavor, higher content of sugars, $\mathrm{pH}$, vitamin $\mathrm{C}$, anthocyanins, isoflavonols, carotinoids and other phenolic compounds, phosphorus, ferrum and magnesium, trace elements ( $\mathrm{Zn}, \mathrm{Cu}$ and $\mathrm{Cr}$ ), but lower - of potassium and calcium $[11,12]$. At the same time, works of Döring J et al. show that the organic farming in grape cultivation influences physiological condition of grape vine, its growth and cropping capacity, but does not affect the quality of grapes [13]. There is practically no information in the literature sources on the effect of the organic farming system on the activity of polyphenol oxidase and the content of $\mathrm{SO}_{2}$-binding components in grapes and wine. These indicators are very important from the point of view of organic winemaking, since they determine doses of must and wine sulphiting during the processes of production and storage $[14,15]$. The sulfur dioxide content in organic wines is limited by national and international winemaking regulations, determining the relevance of research in this direction. Present publication shows study results of the effect of using the organic farming system on the composition and quality of grapes and wines.

\section{Materials and methods}

\subsection{Conditions of growing grapes and schemes of treatment}

The studies were carried out in 2019-2020 on grapes of 'Bastardo magarachskiy' cultivar (V. vinifera), grown in the South Coast soil and climatic area of Crimea. Planting scheme was $3.0 \times 1.5 \mathrm{~m}$. The total area of vineyards used in the study was 3 ha.

The most common grape disease in the conditions of the South Coast of Crimea is oidium, which is a basis for choosing the following preparations and schemes for experimental research:

- the control system of farming provided the protection of plants with the use of chemical agents (CCPA) according to the scheme, adopted in farming. The scheme included 8 treatments, starting with the growth of shoots and inflorescences and finishing in 2 weeks before harvesting, with preparations: Kocide $2000\left(2 \mathrm{~kg} \mathrm{ha}^{-1}\right)$, Topaz, EC $(0.4 \mathrm{~L}$ ha-1), Talendo, EC (0.2 L ha-1), Dynali, (DC) (0.7 L ha-1), Falcon, EC (0.4 L ha-1), Collis, SC (0.5 L ha-1).

- the organic farming system (experiment) included the variant that did not provide treatment of grapes with any plant protection agents ("without treatment”), and 3 variants 
of plant treatment: with biological preparation Respecta $\left(4 \mathrm{~L} \mathrm{ha}^{-1}, 9\right.$ times per growing season); Chitosan (1.015\% solution, 9 times per growing season); with preparations Extrasol (4 l/ha, 8 treatments) and Tiovit Jet (TJ), WDG (6 kg ha-1, 6 treatments), six times - in a tank mixture. The first spraying was carried out during the period of separation of 5-6 leaves, next sprayings coincided with the same grape growth stages, as when using the CCPA.

All preparations used in the organic farming system are of Russian production. Extrasol is an immunizing fungicide, which leads to changes in the metabolism of plant tissues, preventing the infection with fungal and bacterial diseases; contains cells of Bacillus subtilis and products of their metabolism. Respecta is a biological fungicide that affects phytopathogenic microorganisms, producing a wide range of antibiotic metabolites; contains live cells of the bacteria Pseudomonas aureofaciens and products of their metabolism. Chitosan mobilizes the protective system of plants, stimulates growth and development of plants; contains the aminopolysaccharide chitosan, derived from carapace. Tiovit Jet is a preparation with fungicidal and acaricidal action; contains up to $80 \%$ of allotropic modification of bivalent sulfur (S8).

The progression of oidium on bunches in the variant "without treatment" was 33\% in 2019, and 93\% in 2020. The biological efficiency of the chemical plant protection scheme was $82-86 \%$; of the organic protection schemes - from 31\% (Chitosan) to 84\% (Extrasol + TJ) [8].

\subsection{Grape sampling}

To assess the effect of the treatment system on chemical composition of grapes and wine, a combined sample from 20 registered bushes ( 4 replicates by 5 plants each) was collected from all the variants under study. Weight of the combined grape sample was about $20 \mathrm{~kg}$.

\subsection{Preparation of wine samples}

Healthy bunches were used for preparation of experimental wine samples, as well as for the analysis of chemical composition of grapes and wines. The wines were produced in 2 replicates in the conditions of micro-winemaking. The wine production technology provided for crushing grapes with destemming, sulfiting of the must at the rate of $75 \pm 5$ $\mathrm{mg} \mathrm{L}^{-1}$ of the total $\mathrm{SO}_{2}$, fermentation of the must on I-250 yeast strain from the Collection of Winemaking Microorganisms of the Institute Magarach at a temperature of $22 \pm 3{ }^{\circ} \mathrm{C}$ in glass container with a swimming cap and punching-down 7-8 times a day, pomace pressing while fermenting $2 / 3$ of sugars from their original amount, fermentation of the must dry, clarification and decantation of wines.

\subsection{Chemical analysis of grapes and wine}

When determining technological stock of phenolic compounds (TS PhC) in grapes, we crushed berries, heated the resulting pomace and kept it in a temperature-regulated chamber at $70{ }^{\circ} \mathrm{C}$ for $30 \mathrm{~min}$ under agitation. After the pomace cooling, we separated the must by pressing. In all other cases, when analyzing grapes, we used the must, obtained by hand crushing of whole berries.

Before analysis, the must and wine were centrifuged at $5000 \mathrm{rpm}$ for 15 minutes. Sample preparation and determination of grape phenolic maturity indicators were carried out according to the method of Glories Y. et al. [16]. The activity of polyphenol oxidase (PPO) was assessed in the fresh must using the colorimetric method according to the pyrocatechol oxidation rate. Concentration of phenolic compounds $(\mathrm{PhC})$ in must and wine 
was determined using the Folin \& Ciocalteu reagent [17]; of ketoacids - colorimetrically according to their ability to react with 2,4-dinitrophenylhydrazine; of aldehydes - using the titrimetric method [17]. The sugar concentration in grapes and wine, titratable acids in equivalent to tartaric acid and the content of ethanol were determined in accordance with the methods of OIV [18].

Evaluation of the redox condition of phenolic complex of wines was carried out using the potentiometric method based on the ability of phenolic substances to react with iodine, the amount of which was used to judge the degree of reduction of phenolic substances with their ability to further oxidation [17]. The specific reductive ability of phenolic compounds with regard to iodine $\left(\mathrm{I}_{2} / \mathrm{PhC}, \mathrm{ml} \mathrm{L}^{-1} / \mathrm{mg}\right)$ and specific change in the redox potential ( $\mathrm{dEh} / \mathrm{PhC}, \mathrm{mV} \mathrm{L}^{-1} / \mathrm{mg}$ ) were determined. The color intensity (I) of wines was calculated as a sum of optical density values at wavelength of 420, 520 and $620 \mathrm{~nm}$; color hue $(\mathrm{H})-\mathrm{a}$ quotient of optical density values at wavelength of 420 and $520 \mathrm{~nm}$.

\subsection{Statistical data analysis}

All chemical tests were performed in triplicate. Mathematical entries were processed with the SPSS Statistics 17.0 software package using ANOVA. The illustrative material with the text of the article presents arithmetic mean values of the indicators with standard deviation. Statistical significance of differences in the chemical composition of wines from grapes grown in the control and organic farming systems was assessed on the basis of the Student's t-criterion - the difference was considered significant when $\alpha \leq 0.05$.

\section{Results and discussion}

In the course of two-year research, we revealed some differences in grapes obtained in the organic and conservative farming systems in terms of the carbohydrate-acid complex indicators, as illustrated in Table 1. Using of biological preparations in the organic farming system, compared with the chemical plant protection system, led to an increase in the sugar content in grapes on average by $15 \%(\mathrm{t}=2.81$, at $\alpha=0.03)$ : in the first variant the content of sugars consisted of $174 \pm 2 \mathrm{gL}^{-1}$, in the second one $-200 \pm 13 \mathrm{gL}^{-1}$. In grapes obtained in the variant "without treatment", the increase in the sugar content relative to the control was 26\%. At the same time, when treated with Chitosan and Extrasol + Tiovit Jet preparations for 2 years, there was a decrease in the content of titratable acids in grapes by $10 \%$ in comparison with the adopted control system of farming.

Table 1. The content* of sugars and titratable acids in grapes.

\begin{tabular}{|l|c|c|c|c|}
\hline \multirow{2}{*}{ Treatment scheme } & \multicolumn{4}{|c|}{ Indicator / crop year } \\
\cline { 2 - 5 } & \multicolumn{2}{|c|}{$\begin{array}{c}\text { Concentration of sugars, } \\
\text { gL }^{-1}\end{array}$} & Concentration of titratable acids, $\mathrm{gL}^{-1}$ \\
\cline { 2 - 5 } & 2019 & 2020 & 2019 & 2020 \\
\hline without treatment & 191 & 250 & 6,6 & 8,7 \\
\hline Respecta & 202 & 191 & 7,0 & 8,2 \\
\hline Chitosan & 202 & 194 & 6,2 & 6,5 \\
\hline Extrasol + TJ & 188 & 223 & 6,7 & 7,2 \\
\hline CCPA & 172 & 175 & 7,1 & 7,7 \\
\hline
\end{tabular}

* arithmetic mean value of the indicator; standard deviation is less than $4 \%$

In our opinion, when growing grapes for the production of organic wines, special attention should be paid to studying the effect of the used farming system not only on the 
indicators of the carbohydrate-acid complex, but also on the content of phenolic compounds and the $\mathrm{SO}_{2}$-binding complex.

The obtained results show (Fig. 1) that the effect of the farming system on the content of the $\mathrm{SO}_{2}$-binding complex components is largely determined by the crop year. Thus, the content of pyruvic acid in grape batches obtained in the system of adopted conservative farming was $46.0 \pm 2.3 \mathrm{mg} \mathrm{L}^{-1}$ in 2019 , and $9.5 \pm 0.4 \mathrm{mg} \mathrm{L}^{-1}$ in 2020 . The indicator value in respect to the system of organic farming (including the variant "without treatment") ranged from 12.2 to $24.5 \mathrm{mg} \mathrm{L}^{-1}$ in 2019, and from 14.5 to $19.4 \mathrm{mg} \mathrm{L}^{-1}$ in 2020 . Using of preparations Chitosan, Respecta and Extrasol + Tiovit Jet in grape crops of 2019 has led to a decrease in the content of pyruvic acid in the must by an average of 1.9-3.8 times and, on the contrary, to its increase by an average of 1.5-2.0 times in 2020. The content of $\alpha$ ketoglutaric acid in grape samples was in the range of 22.2-63.9 $\mathrm{mg} \mathrm{L}^{-1}$ in 2019 and 8.4$24.8 \mathrm{mg} \mathrm{L}^{-1}$ in 2020 . On the present stage of study there is no general trend in changing of the content of $\alpha$-ketoglutaric acid in grapes obtained when using the biological preparations. So, for example, the consistent use of preparations Tiovit Jet and Extrasol in 2019 was accompanied by an increase in the content of $\alpha$-ketoglutaric acid by 1.4 times, and in 2020 - by its decrease by 1.4 times compared to CCPA. The concentration of aldehydes in grapes of the control and experimental batches was in 2019 and in 2020 on the level of 25.4-32.6 $\mathrm{mg} \mathrm{L}^{-1}$ and 13.7-16.6 $\mathrm{mg} \mathrm{L}^{-1}$, respectively. Regardless of the crop year, using of the organic plant protection schemes against oidium, as well as the variant "without treatment", did not have a significant impact on the content of aldehydes in berries relative to the control schemes of treatment with CCPA.

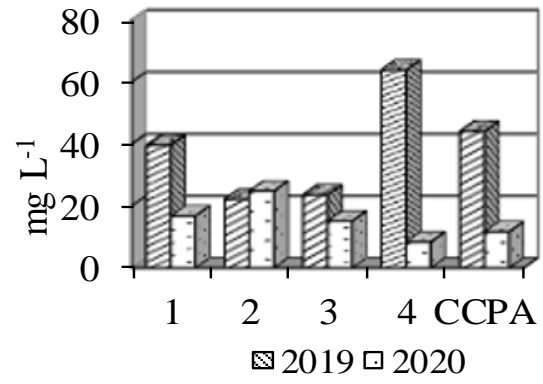

$\alpha$-ketoglutaric acid

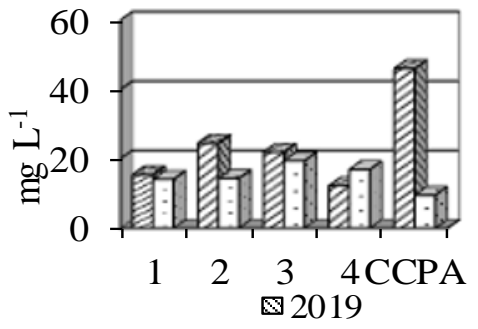

pyruvic acid

1 - without treatment; 2 - Respecta; 3 - Chitosan; 4 - Tiovit Jet + Extrasol; 5 - CCPA

Fig. 1. The $\mathrm{SO}_{2}$-binding complex of the 'Bastardo magarachskiy' grape cultivar, obtained in traditional and organic farming systems (means \pm SD $(\mathrm{SD}<8 \%)$ ).

It follows from Table 2 that regardless the crop year, using of biological preparations was leading to an increase in the content of technological stock of phenolic compounds (on average, by $13 \%$ in 2019 and by $22 \%$ in 2020) and the potential amount of anthocyanins (by 23\%), relative to the concentration of components in grapes obtained in the conditions of CCPA. At the same time, the content of easily extractable anthocyanins (Ea) in berries was decreasing by 1.4 times and the content of seed tannins (Mp) was increasing: 2019 - by 3.2 times; 2020 - by 1.4 times. This fact is a negative factor in the production of red wines: increased content of seed tannins can lead to roughness and excessive astringency of wine flavor, and a decrease in the content of anthocyanins due to their lower extractability from berry skin can lead to a weak and unstable wine color [19]. However, in our case, grapes of both control and experimental batches were considered to be phenolic maturity: a content of easily extractable anthocyanins $\geq 45 \%$ and a content of seed tannins $\leq 15 \%$. The PPO 
activity of grape must from the control batches ranged from $0.066 \pm$ (2019) to $0.150 \pm$ c.u. (2020). Using of biological preparations in the organic scheme of plant protection led on average to the twofold increase $(\alpha<0.05)$ in the PPO activity of the must in 2019, and by $7 \%$ in 2020. The biggest increase in the PPO activity of the must was observed during two consecutive years of treatment grapes with Extrasol and Tiovit Jet preparations, the smallest - with Respecta preparation. The maximum PPO activity (250 \pm c.u.) was registered in grapes of 2020 crop year, obtained in the variant "without treatment".

Table 2. Indicators of phenolic complex and oxidase activity of grapes (means $\pm \mathrm{SD}$ ).

\begin{tabular}{|l|c|c|c|c|c|}
\hline $\begin{array}{l}\text { Treatment } \\
\text { scheme }\end{array}$ & $\begin{array}{c}\text { TSPhC, mg } \\
\mathrm{L}^{-1}\end{array}$ & $\begin{array}{c}\text { Anthocyanins, } \\
\mathrm{mg} \mathrm{L}^{-1}\end{array}$ & Ea, \% & Mp, \% & PPO, c.u. \\
\hline $\begin{array}{l}|c| \\
\text { without } \\
\text { treatment }\end{array}$ & $1822 \pm 182$ & $845 \pm 80$ & $61 \pm 5$ & $2 \pm 0.5$ & $0.163 \pm 0.016$ \\
\hline Respecta & $2886 \pm 144$ & $1145 \pm 80$ & $46 \pm 2$ & $3 \pm 1$ & $0.079 \pm 0.006$ \\
\hline Chitosan & $2292 \pm 183$ & $1241 \pm 84$ & $43 \pm 3$ & $9 \pm 2$ & $0.096 \pm 0.008$ \\
\hline $\begin{array}{l}\text { Extrasol }+ \\
\text { TJ }\end{array}$ & $2328 \pm 93$ & $1057 \pm 53$ & $55 \pm 3$ & $4 \pm 1.5$ & $0.220 \pm 0.015$ \\
\hline CCPA & $2228 \pm 134$ & $938 \pm 49$ & $60 \pm 4$ & $2 \pm 1$ & $0.066 \pm 0.005$ \\
\hline \multicolumn{7}{|c|}{2020} \\
\hline $\begin{array}{l}\text { without } \\
\text { treatment }\end{array}$ & $2631 \pm 210$ & $1199 \pm 96$ & $55 \pm 4$ & $16 \pm 3$ & $0.250 \pm 0.023$ \\
\hline Respecta & $1684 \pm 118$ & $821 \pm 66$ & $64 \pm 5$ & $11 \pm 2$ & $0.156 \pm 0.017$ \\
\hline Chitosan & $1805 \pm 72$ & $1349 \pm 94$ & $46 \pm 4$ & $14 \pm 2$ & $0.156 \pm 0.014$ \\
\hline $\begin{array}{l}\text { Extrasol } \\
\text { TJ }\end{array}$ & $2708 \pm 135$ & $835 \pm 50$ & $52 \pm 4$ & $19 \pm 2$ & $0.170 \pm 0.014$ \\
\hline CCPA & $1695 \pm 119$ & $814 \pm 48$ & $83 \pm 5$ & $12 \pm 1$ & $0.150 \pm 0.017$ \\
\hline
\end{tabular}

In our opinion, the presented entries are explained by mobilization of the plant selfdefense system in the organic farming, with or without using of the studied preparations, where phenolic and oxidase complexes play a significant role [20, 21].

The revealed differences in chemical composition of the 'Bastardo magarachskiy' grape cultivar, obtained in various farming systems, were reflected in the physicochemical characteristics of the wines.

The concentration of ethyl alcohol in the control variants of wines was $10 \pm 0.5 \%$ vol. In wines from grapes, obtained in the organic farming system, including the variant "without treatment", it varied from 11.3 to $11.9 \%$ vol. The concentration of residual sugars in the experimental and control wines did not exceed $1.7 \mathrm{gL}^{-1}$. The content of titratable acids (equivalent to tartaric acid) in the experimental wines ranged from 4.2 to $5.2 \mathrm{gL}^{-1}$, which is 1.2 times less than the indicator value in the control wine samples.

The Fig. 2 illustrates that concentration of phenolic compounds averaged $1034 \pm 83 \mathrm{mg}$ $\mathrm{L}^{-1}$, including anthocyanins $140 \pm 10 \mathrm{mg} \mathrm{L}^{-1}$, in wine samples from grapes of the control system of farming. Wines from grapes obtained in the system of organic farming, affected by the use of biological preparations or "without treatment", differed $(\alpha<0.05)$ in a higher (on average by 46\%) content of phenolic compounds and anthocyanins (1.6 times on average), resulting in a more saturated color range of wines - the values of color intensity indicator exceeded those in the control wine batches by 1.4 times (Fig. 2). 

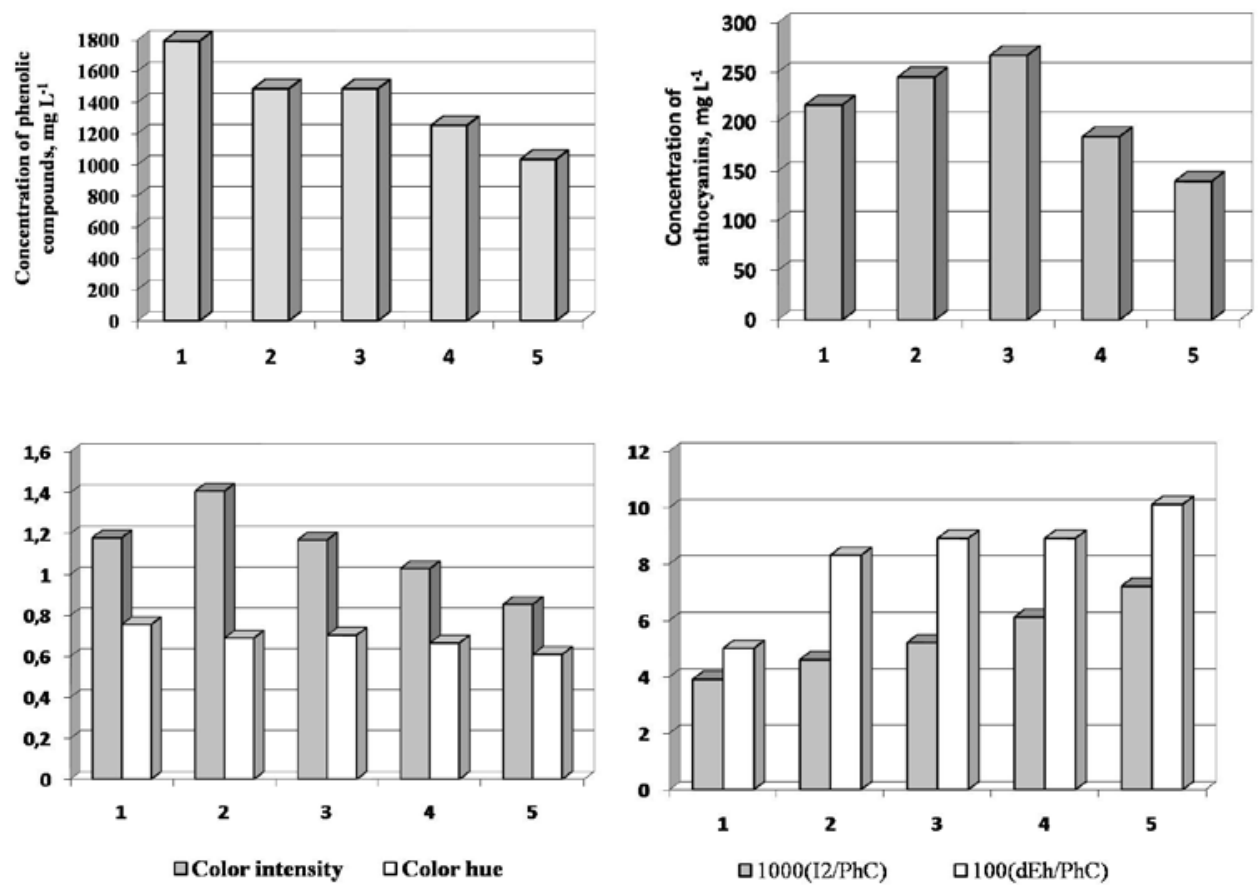

1 - without treatment; 2 - Respecta; 3 - Chitosan; 4 - Tiovit Jet + Extrasol; 5 - CCPA

Fig. 2. Indicators of chemical composition and physicochemical properties of wines from grapes of the organic and control farming systems

As follows from the data presented in Fig. 2, wines from grapes obtained in the organic farming system were characterized by a more oxidized phenolic complex. First of all, this is evidenced by a decrease in the specific reducing capacity of phenolic compounds in relation to iodine by an average of $31 \%$ and a specific change in the redox potential during the iodine titration - by an average of $23 \%$. The most significant decrease in indicators (by $46-$ $50 \%$ ) relative to those in control wines was noted when using grapes obtained in the variant "without treatment"; the least (by 12-15\%) - in wines from grapes obtained with the consistent use of Extrasol and Tiovit Jet preparations. Secondly, the oxidation of the phenolic complex in experimental wines is evidenced by intensification of brown tones, recorded at a wavelength of $420 \mathrm{~nm}$. In the context of wines from grapes obtained against the background of using preparation Chitosan and in the variant "without treatment", the color hue has increased $(\alpha<0.05)$ by $15 \%$ and $24 \%$, respectively, relative to the control wine samples. In wines from grapes obtained with the use of Extrasol and Tiovit Jet preparations, changes in the color hue were insignificant and amounted to $9 \%$.

With regard to the $\mathrm{SO}_{2}$-binding complex of wines, the following was observed. The content of pyruvic and $\quad \alpha$-ketoglutaric acids in wines from grapes obtained in the system of adopted traditional farming was $22.0 \pm 1.3 \mathrm{mg} \mathrm{L}^{-1}$ and $64.2 \pm 4.7 \mathrm{mg} \mathrm{L}^{-1}$. In wines from grapes obtained in the organic farming system, the concentration of pyruvic and $\alpha$ ketoglutaric acids was, on average, 1.5 and 2.0 times higher than in the control (Fig. 3). The greatest increase in the content of $\alpha$-ketoglutaric acid was recorded in experimental wines from grapes obtained in the variant "without treatment" (2.2 times), of pyruvic acid - when using Chitosan preparation (2.0 times). Along with this, the experimental wine batches differed in a lower concentration of aldehydes (by 20\%): from 11.4 to $17.0 \mathrm{mg} \mathrm{L}^{-1}$. The analysis of the obtained results showed that the smallest concentration of $\mathrm{SO}_{2}$-binding 
components was characteristic of wines from grapes obtained in the organic farming system when using Extrasol and Tiovit Jet preparations.
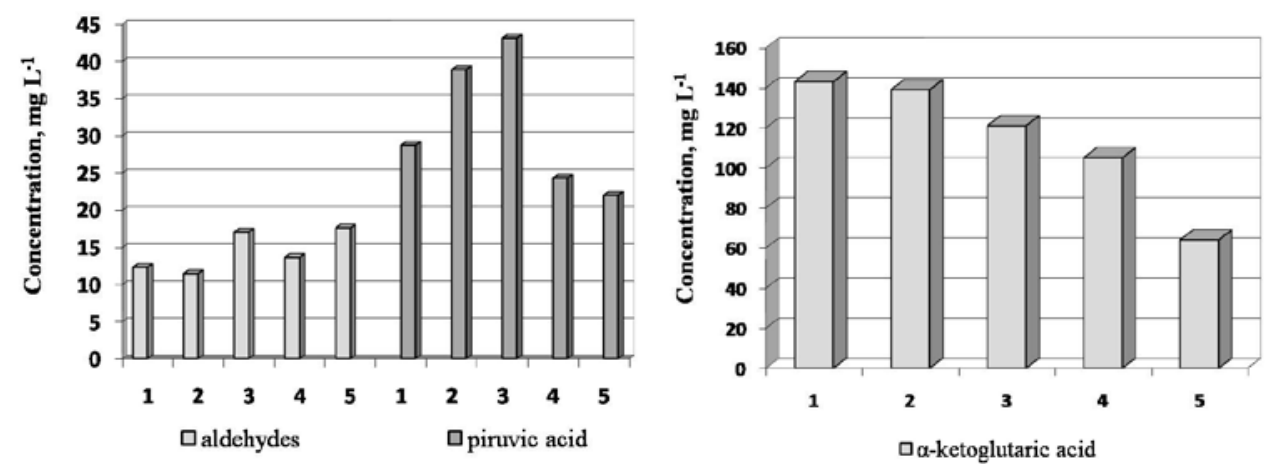

1 - without treatment; 2 - Respecta; 3 - Chitosan; 4 - Tiovit Jet + Extrasol; 5 - CCPA

Fig. 3. The $\mathrm{SO}_{2}$-binding complex of wines prepared from grapes of the control and organic farming systems

Organoleptic testing of wines did not reveal a significant effect of the farming system on their quality. The experimental and control wines were characterized by ruby color, berry aroma with hints of spices and chocolate, moderately tannin and full-bodied flavor. Tasting evaluation (according to the 8-point system for young wines) ranged from 7.66 to 7.72 points.

\section{Conclusion}

The transition to biologized or organic farming system in general is a requirement of time, aimed at protection of biological diversity of the planet and public health. At the same time, it is necessary to minimize yield losses and ensure high organoleptic quality of food products.

The studies provided made it possible to assess the effect of using the preparations against oidium based on the bacteria Bacillus subtilis (Extrasol) and Pseudomonas aureofaciens (Respecta), the aminopolysaccharide chitosan, derived from carapace (Chitosan), the sulfur allotrope (Tiovit Jet) in the organic farming system on the quality of 'Bastardo magarachskiy' grapes and red wines. It was found that, in comparison with the traditional farming system based on using chemical plant protection agents, the organic schemes of grape treatment contributed to a significant $(\alpha<0.05)$ accumulation of sugars, phenolic substances, including anthocyanins, in berries and the polyphenol oxidase activity of the must. At the same time, using of preparations in the system of organic farming led to an increase in the proportion of seed tannins and a decrease in the proportion of easily extractable anthocyanins in the phenolic complex. The experimental grape treatment schemes did not affect the accumulation of aldehydes in berries, and their effect on the content of ketoacids was determined by the crop year conditions. Difference in the chemical composition of grapes, obtained in various farming systems, was reflected in physical and chemical characteristics of wines. The experimental batches of wines were distinguished by a higher $(\alpha<0.05)$ content of ethyl alcohol, phenolic substances (on average by 46\%), anthocyanins (1.6 times), pyruvic and $\alpha$-ketoglutaric acids (1.6 and 1.9 times) and a lower (by $20 \%$ ) concentration of aldehydes. The experimental wines were characterized by a more oxidized phenolic complex and intense color. Using of biological preparations in order to protect grapes of 'Bastardo magarachskiy' cultivar from oidium did not have a significant effect on organoleptic properties of wines. 
In general, in terms of biological efficiency, combination of physicochemical and organoleptic characteristics of grapes and wines, the best result from the standpoint of organic winemaking, concerning, in particular, the reduction of $\mathrm{SO}_{2}$-loading in technological cycle, was shown by the consistent use of preparations Tiovit Jet and Extrasol in the experimental conditions of the organic farming system.

\section{References}

1. S.I. Korzhov, Bulletin of the Voronezh State Agrarian University, 3(26), 4(2010) (in Russian)

2. E.A. Ivantsov, Bulletin of the Volgograd State University, 1(5), 6(2013) (in Russian)

3. A.P. Ostapenko, E.M. Falynskov, Bulletin of the Don State Agrarian University, 4(14), 6(2014) (in Russian)

4. N.G. Zakharova, Z.Yu. Sirayeva, I.P. Demidova, S.Yu. Yegorov, Scientific works of Kazan State University, 148(2), 10(2006)

5. T.P. Sabirova, R.A. Sabirov, Bulletin of the AIC of the Upper Volga region, 3(43), 5(2018) (in Russian)

6. V.S. Kursakova, Bulletin of the Altai Agrarian University, 2(112), 5(2014) (in Russian)

7. E.P. Stranishevskaya, Ya.A. Volkov, M.V. Volkova, E.A. Matveikina, N. I. Shadura, V. A. Volodin, Magarach. Viticulture and Winemaking, 22(4), 8(2020)

8. E. Stranishevskaya, E. Ostroukhova, I. Peskova, S. Levchenko, E. Matveikina, N. Shadura, E3S Web of Conferences, 161, 01070, 5(2020)

9. J.P. Reganold, P.K. Andrews, J.R. Reeve, L. Carpenter-Boggs, C.W. Schadt, J.R . Alldredge, C.F. Ross, N.M. Davies, J. Zhou, PLoS One, 5, 14(2010)

10. A.B. Oliveira, C.F.H. Moura, E. Gomes-Filho, C.A. Marco, L. Urban, M.R.A. Miranda PLoS One, 8, 6(2013)

11. X. Yu, L. Guo, G. Jiang, Y. Song, M.A. Muminov, Acta Ecologica Sinica, 38, 8(2018)

12. A. Miele, BIO Web of Conferences, 7, 01011, 4(2016)

13. J. Döring, M. Frisch, S. Tittmann, M. Stoll, R. Kauer, PLoS One, 10(10), e0138445, (2015)

14. J.N. Jackowetz, R.M. de Orduña, Food Control, 32(2), 6(2013)

15. M.C. Santos, C. Nunes, J.A. Saraiva, M. A. Coimbra, Food Res. Technol., 234, 12(2012)

16. K.A. Joutei, D. Bouya, C. Saucier, Y. Glories, Cah. Agric, 15, 4(2006)

17. V.G. Gerzhikova, Methods of technochemical control in winemaking (Tavrida, Simferopol, 2009)

18. Compendium of international methods of wine and must analysis (Paris, 2017)

19. E.V. Ostroukhova, I.V. Peskova, P.A. Probeigolova, G.N. Verik, Magarach. Viticulture and Winemaking, 1, 3(2012) (in Russian)

20. E. N. Oleshuk, A. N. Grits, E. G. Popov, T. G. Yanchevskaya, Bulletin of the National Academy of Sciences of Belarus, 4, 9(2016) (in Russian)

21. N.N. Karpun, E.B. Yanushevskaya, E.V. Mikhailova, Agricultural Biology, 50(5), 10(2015) (in Russian) 